\title{
Exploring the Possible Gaps Associated with the Current Practice and Application of Psychodynamics in Contemporary Clinical Settings in Some African Countries
}

\author{
Prof. S. M Kang'ethe \\ University of Fort Hare, Department of Social Work and Social Development \\ Box X1314, ALICE. 5700, South Africa \\ Doi:10.5901/mjss.2014.v5n8p539 \\ Email addresses: skangethe@ufh.ac.za

\begin{abstract}
The role of psychodynamics in deciphering and determining the behaviours of people remains central in diagnosing and treating behaviours and abnormalities that can only be explained psycho dynamically. The aim of this article is to explore and discuss possible gaps embedded in the continuum of psychodynamics with the hope of coming with interventions that can make psycho dynamically processes such as counselling effective in African societies. Findings indicate the following gaps: most psychodynamic challenges in most societies are handled by traditional practitioners; there is generally inadequate application of psychodynamics due to inadequate infrastructure and human resource; the use of cultures to inform most psycho dynamically oriented challenges; and most clinical practitioners to offer psychodynamic services have been deployed to handle HIVIAIDS. The article recommends the use of traditional and clinical psychodynamic services in tandem; and expedition of training of clinical based professionals/paraprofessionals/ auxiliary workers.
\end{abstract}

Keywords: Counselling, collaboration, resources, traditional practitioners, modern practitioners

\section{Introduction}

Conceptually, psychodynamics also known as dynamic psychology is a psychological oriented discipline that emphasizes systematic study of the psychological forces that underlie human behavior, feelings, and emotions and how they might relate to early childhood experience (Freud, 1964; Maguire, 2002; Eriksson, 1968). While the application of psychodynamic theories still remain very applicable to many settings in societies, especially in determining behaviours and traits, as well as facilitating the change of undesirable behaviours to desirable ones, it is perhaps important to look at the apparent gaps associated with its application in changing or positively influencing the behaviour of people. This is to make them adapt to their social milieu and functional optimally to be good citizens of their countries (Freud, 1964; Eriksson, 1968; Maguire, 2002). To say the least, people's behaviour has been a product of external factors and sociopolitical dynamics of development such as globalization. These have influenced the pace of change within societies and therefore the psychodynamic infrastructure. To this end, the advent and the much desired effects of globalization, westernization, euro centrism, modernization and globalization have, on a positive angle ushered in values that are progressive in nature making developing world experience "much light" as the developed world; usher in new ways of exploiting and tapping the existing resources as well as exploring better ways of communication, education; and be in a position that makes the virtues of the developed world be accessible and available (Kang'ethe, 2013a; Mulinge \& Mufune, 2003;Keyman, 2010); while on the other hand the effects have to been associated with pervasive and perfidious challenges such as unemployment; divorce; drug abuse; mental disturbances; high blood pressure related diseases; and family dysfunctions.

The role of increased dynamism and complexes in the environment become important in determining the causes or aetiology of these diseases; as well as being the reference point for any workable clinical diagnosis (Maguire, 2002; Segal et al, 2007). The role of environment based theories, therefore, such as system theories, ecological theories and person- in- environment theories as possible aiding tools become significantly central to any possible clinical diagnosis. These environment- based clinical challenges continue to beg for answers as to how best to offer successful clinical diagnosis, with little success. This is partly because there are no adequate clinical and therapeutic institutions to work on the challenges, coupled with inadequate awareness of such facilities; and poverty of the individuals experiencing these challenges (Corwin, 2002; Ehrenkranz, 1989). These eclectic and complex challenges to handle psychodynamic challenges have had disastrous health effects such as the increased high blood pressure related challenges and diseases. No wonder high blood related diseases are increasingly becoming the cause of many deaths today in developing countries. It never used to be the same several decades back. The below discussions will centre on the 
possible gaps associated with psychodynamic practices and interventions in the contemporary societies of African countries.

\section{Problem Statement}

While psychodynamic theories may have been discredited especially by the behaviourists, all is not lost that they continue to decipher and explain the behaviour of individuals. However, all types of psychodynamics traits and practices whether traditional or modern clinical practices heavily use the theoretical underpinning of psychodynamics. However, it is good to explore and discuss possible gap areas associated with the terrain of psychodynamics especially the fact that some psycho dynamically oriented processes such as modern counselling have not adequately been understood or used widely. Perhaps the gap and an appreciation of the continuum of psychodynamics from traditional practices to the modern counselling processes need to be appreciated and understood. An exploration of such gaps in psychodynamics may call for possible interventions to lobby and market the various psychodynamic processes such as counselling; or come out with ways in which traditional and modern psychodynamic oriented processes can be blend or work in tandem.

\section{Methodology}

The article has utilized the review of literature methodology to explore gaps embedded in the application of psychodynamic process in effectuating behaviour change, or handling some behaviour related abnormalities. The article has used books, journals, United Nations publications and the researcher's intuitive wisdom and experience in teaching clinical social work

\section{Gaps and Challenges Associated with Psychodynamic Application/Interventions}

\subsection{Psychodynamic related challenges handled by traditional practitioners}

The term psychodynamics is not among the very common terms in the world of diseases or abnormalities to ordinary masses. This could partly explain why the psychodynamic challenges especially in many developing countries are not adequately understood, especially their diagnosis (Maguire, 2002). In many varied contexts, many cases that require clinical diagnosis have been handled through the use of traditional practitioners that people have known since time immemorial and therefore developed faith and trust in their therapies (Kang'ethe, 2012, 2013b). Therefore, many African societies have had measures in place to surmount, solve or resolve socially disturbing events such as psychiatric cases, family wrangles, family crisis, tribal boundary conflicts, and generally perturbing mental cases. The solution has been culturally grounded or exploits the immense social capital embedded in people's cultures and faith systems (Mbuya, 2000; Byamugisha et al., 2002). In this context, culture and by extension, cultural based tools have been instrumental in problem solving exercises (Afolayan, 2004; Kang'ethe, 2013b,c,d). However, most of these challenges may be purely social, although the border at which they may have become clinical may not succinctly be defined or delineated (Maguire, 2002; Payne, 2005).

In many traditional societies, bereavement and grief counselling was overcome through clan and group associations to help end the mourning and prepare the deceased to cope with the aftermaths of the dreadful event (Uys \& Cameron, 2003; NAB, 2004). The role of allegiance to neighbourhood, clanism, age group, women group, youth group and other culturally ordained social networks offered a panacea of healing and problem solving endeavours (Byamugisha et al., 2002; Kang'ethe, 2011, 2013c,d). These culturally based therapies had a strong psychotherapeutic component, however.

Contrastingly, many people in many societies today are increasingly using counselling and its possible therapeutic or remedial effects to individual with social problems such as increased family strives between husbands and wives; its potent to increase coping with a disease; coping with a drunken husband; or being able to go through a traumatizing event such as the loss of a loved one (Nurses Association of Botswana (NAB), 2004; Uys and Cameron, 2003; Maguire, 2002; Corey, 2005). But contrastingly and ironically, the current aspects of social treatment and diagnosis of social problems necessitating clinical diagnosis is only currently gaining mileage in developing countries (Payne, 2005; Maguire, 2005). Most of these clinically diagnosable challenges were seen as something that could not be changed, with some societies pointing to bad fate, the work of spirits and sometimes the "eyes" of the jealousy neighbours (Mbuya, 2000; Afolayan, 2004; Kang'ethe, 2013 c,d). In some cases, the use of cultural traditional therapists was applied to handle this clinical diagnosis. Empirical evidence holds that some of these cultural practitioners were knowledgeable enough to be 
able to avert some of the clinical symptoms leading to some degree of success, if not total recuperation (Kang'ethe, 2009a, 2012; UNAIDS, 2000).

\subsection{The dearth of psychotherapeutic application}

With burgeoning cases of clinically associated diseases, increased social tensions, societal dysfunctions and community upheavals due to immense social problems prompting specialized clinical diagnosis, the niche, place, and pace of psychodynamic ally oriented institutions in most societies of the developing world as a tool of handling these immense clinical social challenges needs to be investigated (Maguire, 2002;Corwin, 2002). While the psychotherapeutic counselling is increasingly becoming known and on use especially with the advent of HIVIAIDS, this researcher thinks that the psychodynamic application is still not adequate. The extent to which many social dysfunctions can be handled psycho dynamically still remains unknown or realizable in developing countries. There are many reasons that abounds to this. First a score of scholars especially the behaviourists had strongly discredited the work of Sigmund Freud and this could have made many practitioners to develop their diagnosis using psychodynamic theories, or take the process for granted. Secondly, clinical and psychological knowledge useful in clinical diagnosis has not adequately spread in many infrastructural institutions in the countries of the developing countries. For example many governments have not been able to employ school social workers to handle some psychodynamic challenges that may be impeding learners from achieving their optimal functioning in learning (Rogers, 1977). Even in hospitals, the role of clinical social practitioners is never viewed as very important with many people believing in therapeutic process that entails dispensing medication, while issues of psychodynamics or process may be responsible for certain behaviour pattern are given a low preference.

\subsection{Cultural practitioners offering social diagnosis of social problems in traditional societies}

However, many societies are known to result to the use of cultural based virtues of solving and resolving a myriad of clinical based challenges. The use of presumed elderly wise men and women in most cultures of Africa has been an accepted norm of facilitating an understanding between the conflicting parties as in the case of marriage challenges (Afolayan, 2004; Mogogi, 2001). The Batswana culture, for instance, has been rich in methodologies of solving and resolving social strives and conflicts. The concept of therisanyo mmogo (consulting one another to reach a consensus); and kutlwano (listening to one another to resolve or settle an issue) have been internalized in many Batswana communities. This researcher who has stayed in Botswswna for over ten years bears testimony that these values have been adequately operationalized. Perhaps this could contribute to the fact that Botswana remains one of the peaceful countries in the region and in Africa generally (Kang'ethe \& Rhakudu, 2010). These processes have been done or presided by respected elders in the community. In the same ven, the country value reinforcing messages of making peace through proverbs such as susu ilela suswana (even the deaf should listen to one another). This implores the need to give one another space while making dialogue or discussing as a way of winning peace among all (Kang'ethe \& Rhakudu, 2010). However, with increased modernization, euro centrism, westernization and globalization, these virtues appear to be overtaken by events, calling for a replacement to address these social based challenges. The role of psychodynamic ally driven processes, then , becomes the answer..

\subsection{Inadequate training of clinical practitioners in developing world}

Psychodynamic practice such as the social work cannot have adequate meaning as a helping profession if it is not equipped with specific values, norms, and importantly with specific skills to match the problem at hand (Segal et al., 2007; Sheafor \& Horejsi, 2008). Although many social work gurus and practitioners have indicated the need to conceptualize, contextualize, reconceptualise and possibly work towards overhauling the social work education curriculum as it has been found to embrace acute discrepancies in the face of innumerable and emerging challenges in the societies (Mupedziswa, 2001, 2005; Osei Hwedie, 1996; Osei Hwedie \& Rankopo, 2008), it is equally pertinent that psychodynamic social practitioners such as the social workers, auxiliary workers and counsellors are equipped with specific specialized skills. One area in dire need of specialized skills is in psychotherapeutic management and discharge of services. Incontrovertibly, our social work institutions are not training adequate clinical based social workers. Although in South African universities the undergraduate course has had a clinical component introduced, it is not adequate to make social workers competent clinical social workers. Perhaps this is why many countries believe that specialized clinical social work should be handled at the master's level. Inarguably, many countries of Africa, such as South Africa, Botswana or other African countries have very few clinical social workers. 
Paradoxically, it is assumed that certificate holder social work paraprofessionals or auxiliary social workers are competent enough to handle complicated clinical based psychotherapeutic cases. This has thrown psychodynamic activities such as counselling into disarray. Besides lack of clinical social workers, empirical research indicates that in many contexts of the developing world, they even lack adequate counsellors who may have been certificate holders. In a research by Kang'ethe in Botswana, caregivers taking care of persons living with HIVIAIDS reported being overwhelmed by caring duties and tasks due to the fact that counselling or any possible psychotherapeutic assistance was not availed to them or not available at all (Kang'ethe, 2010a,b) That could have informed and determined the high death toll the care programme was experiencing (Kang'ethe, 2010a,b). Though the state of resources could explain the low number of clinical social workers in countries such as Botswana, and South Africa, it is apparent that the policy advocacy and awareness pertaining to their importance as opposed to the generalist social workers, is not given prominence it deserves. Statistics of individuals going to the hospitals because of clinical challenges emanating from apparent social nature such as family dysfunctions, drug abuse, rape, mental challenges call for a serious outlook possibly necessitating adequate training of the clinical social workers. Perhaps on the job training of the generalist social workers, auxiliary social workers, counsellors and any other social work based para-professionals could do good as countries wait to train clinical social workers in droves (UNAIDS, 2001; Petit, 1994).

\subsection{Clinical social workers deployed in HIVIAIDS contexts}

HIVIAIDS in South Africa and Botswana has made policy direction to divert most of the resources to the HIVIAIDS field. Many social workers with clinical training such as psychotherapists, counsellors have been deployed in hospitals and clinical settings to handle HIVIAIDS cases. This, to some extent, has robbed other clients with other clinical challenges of the right to have their challenges addressed. Perhaps it is due to facing this inadequate clinical social workers or generalist social workers that the country of Botswana in 2001 introduced family care model which saw one social worker handle all the challenges that were in one household, instead of the erstwhile arrangement in which the orphans could be handled by the orphan based social worker while HIVIAIDS clients would be handled by a HIVIAIDS based social worker (Kang'ethe, 2010a,b).

\section{The Way Forward}

\subsection{Use of traditional and clinical services in tandem}

Due to the fact that most of the clinical based services are overwhelmed due to lack of human resource, perhaps a policy allowing collaboration of the of modern clinical services and traditional ones needs to be encouraged. This means that clinical practitioners agree that traditional clinicians or practitioners have a role to diagnose some of the clinical conditions. On the other hand advocacy needs to be unleashed to the traditional practitioners to agree to work in tandem with the modern clinicians. The two can mutually enrich one another for the benefit of their clients. Perhaps this is why in a research in Tsabong, Botswana, Kang'ethe (2012) recommends the modern medical practitioners to work in tandem with the traditional healers who were also in trade, some of them with experience to handle some ailments and conditions that the modern medical practitioners could not. Inarguably, this would recognize the role of indigenous knowledge systems and social capital abounds in some skilled individuals for the benefit of the clients (Kang'ethe, 2012).

\subsection{Expedite training of clinical based professionals}

Institutions of higher learning, through policy enforcement from the respective governments need to increase the number they train to handle psychodynamic challenges. With life being overwhelmed by complex psychosocial challenges, this calls for all the service industries or avenues of public be equipped by social workers or other psycho dynamically trained personnel to handle social challenges. The fact that family dysfunctions, quarrels, civil strives, divorce, femicide and passion killing are on increase especially in the Southern African countries is evidence enough that the role of psycho dynamically trained personnel is necessary (UNDP, 2008; Kang'ethe, 2009b).

\section{Conclusion}

Evidence of increased social strives, family dysfunctions, femicide and passion killing indicates the need for services of psychosocial nature. This calls for the governments of respective countries especially in the affected countries to train as 
many social workers, auxiliary social workers and psychologists to handle many of these social challenges. It is crystal clear that many countries are moving from the use of traditional practitioners in tackling some of the psychodynamic challenges their communities have been facing. While the use of modern clinical services is recommended, this researcher recommends a situation in which the modern clinical services and the traditional practice are run in tandem. This is because many poor countries lack enough resources to train adequate modern clinical professionals. A realization that traditional practitioners also possess invaluable indigenous knowledge system to benefit the clients has also prompted the recommendation of the duo practitioners to work in tandem.

\section{References}

Afolayan,, F. (2004). Culture and Customs of South Africa. Westport, Connecticut: Greenwood Press

Byamugisha, G, Steinitz, L.Y., Williams G \& Zondi, P. (2002). Journeys of Faith. Church based responses to HIV and AIDS on three Southern African countries. G \& A Williams, Oxford, U.K.

Corey, G. (2005). Theory and Practice of counselling and psychotherapy. Seventh edition. Thomson Learning. Brooks/Cole

Corwin, M.D. (2002). Brief treatment in clinical social practice. Pacific Grove, California: Brooks/Cole Thomson Learning.

Ehrenkranz, S.M. (1989). Clinical social work with maltreated children and their families: man introduction to practice. New York: New York University Press. Eriksson, E.H. (1968). Identity. Youth and Crisis. New York: Norton Publishers.

Freud, S. (1964). "new introductory lecturers on psychoanalysis". In : Stracher J (ed). The Standard edition of the complete psychological works of Sigmud Freud. Vol 22. London: Hogarth (original work published in 1933).

Kang'ethe, S.M. (2011). Evaluating the role of support group structures as vehicles of palliative care giving productivity in Botswana. Indian Journal of palliative care/Jan-Apr 2011/Nol17/Issue-1/Pp 11-19.

Kang'ethe, S.M. \& Rhakudu, M. (2010). Religious Education book for form 2. Heinemann Publishers, Gaborone.

Keyman, E.F (2010). Modernization, globalization and democratization in turkey: The Akp Experience and its Limits> Constellation 17 (2): $312-327$.

Maguire, L.( 2002). Clinical Social Work. Beyond Generalist Practice with Individuals, Groups, and Families. Brooks/Cole Belmont, CA USA.

Mogogi, K. ( 2001). Youth and culture of Peace. A paper presented at UNESCO Conference at Grand Palm Hotel, 16th February.

Nurses Association of Botswana (NAB). (2004). Caring for the Caregivers. Gaborone, Kgotla Designs PTY LTD, Botswana.

Payne, M. (2005). The Origins of Social Work. Continuity and Change. Palgrave Macmillan.

Uys, L. \& Cameron, S. ( 2003). Home Based HIV/AIDS Care. Oxford University Press.

Kang'ethe, S.M (2009a). Traditional healers as caregivers to HIVIAID patients. Journal of Social Aspects of HIVIAIDS Sahara. Vol. 6 (2). September, 2009. Pp.83-91.

Kang'ethe, S.M. (2009b). "Inadequate male involvement in health issues: The cause of gender skewed HIV and AIDS situations in Botswana". In: Maundeni T, Osei Hwedie B.Z, Mukaamambo E. and Ntseane (eds). Male involvement in Sexual and Reproductive Health. Prevention of Violence and HIVIAIDS in Botswana: 1-28.

Kang'ethe, (S.M 2010a). Exploring the Psychosocial Palliative care giving Position Associated with Kanye HBC Programme. Botswana Notes \& Record Journal. Vol 42: Pp 112-153.

Kang'ethe, S.M. (2010b) . Validating that palliative care giving is a stressful occupation in Botswana care programmes. SAFP Journal. 2010. Vol. 52. No 6. $\operatorname{Pg} 1-9$.

Kang'ethe, S.M. (2012). Attitudes of PLWA and other selected communities in Tsabong towards operationalizing bio medical and traditional therapies in tandem to face the AIDs epidemic. Social Work/Maatskaplike, 2012.46 (1). PP 55-69.

Kang'ethe, S.M. (2013a). Panacea and perfidy of Globalization as an engine of social development in developing countries. Accepted for publication in the Journal of Human Ecology, India.

Kang'ethe, S.M. (2013). Repositioning, Reclaiming and Rejuvenating the Niche of Traditional Practitioners in the face of Modernization in selected African Countries. In the Press of Studies on Ethno-Medicine, India

Kang'ethe, S.M. (2013c). The panacea and perfidy of culture as a platform of behavior change with examples from Botswana and South Africa. In the press of Social Work Practitioner, University of Johannesburg, South Africa.

Kang'ethe, S.M. (2013d). The panacea and perfidy of cultural rites of circumcision in African countries: Examples from Kenya, Botswana and South Africa. EASSRR Journal. Vol. xxix, no 1, pp. 107-123.

Mbuya, J. C. (2000). The AIDS Epidemic in South Africa.Johannesburg, Henco Design.

Mulinge, M.M. \& Mufune, P. ( 2003). Debt Relief Initiatives and Poverty Alleviation. Lessons from Africa. Capetown; African Institute of South Africa. Cape Town.

Mupedziswa, R. ( 2001). The quest for relevance. Towards a conceptual model of developmental social work education and training in Africa. International Social Work. July 2001.Vol 44. No 3: 285-300.

Mupedziswa, R. (2005). Challenges and prospects of social work services in Africa. In J.C. Akeibunor \& E.E Anugwon (Eds). The social sciences and socioeconomic transformation in Africa (pp271-317). Nsuka: Great AP Express Publishing.

Osei-Hwedie, K. (1996). The indigenisation of Social Work Practice and Education in Africa: the Dilemma of Theory and Method. Social Work/Maatskaplike Work, 32 (3): 215-25

Osei-Hwedie, K. \& Rankopo, M. (2008). Developing culturally relevant social work education in Africa: The case for Botswana. In M Gray, J Coates \& MY Bird (Eds). Indigenous social work around the world (Pp203-219). Cornwall: Ashgate.

Petit, P. (1994). Closing the performance gap. Health Action 1994 (8) 4.

Rogers, C. (1977). Carl Rogers on personal power: inner strength and its revolutionary impact. New York: Delacorte Press.

Segal, E.A, Gerdes, K. E \& Steiner, S. (2007). An introduction to the profession of Social Work. Becoming a change agent. Second edition. Thomson. Brooks/Cole.

Sheafor, B. W. \& Horejsi, C. R. ( 2008). Techniques and guidelines for Social Work Practice. Allyn \& Bacon. Boston, London, Sydney \& Toronto.

UNAIDS (2000). Collaboration with Traditional healers in HIV/AIDS prevention and care in Sub Saharan Africa. A literature review. Geneva, Switzerland

UNAIDS (2001). Promoting excellence in training. The Regional Training Network (RATN). UNAIDS Best Practice Collection. June. Geneva, Switzerland.

UNDP (2008). Situation Analysis on Gender Based Violence in Botswana. Draft Report. Participatory Education, Evaluation and Research; Gaborone. UNDP Press office. 